\title{
Microstructures formation and phase transformations around the interface of welds between dissimilar steels
}

\author{
Fanny Mas ${ }^{1}$, Catherine Tassin ${ }^{1}$, Ernst Kozeschnik ${ }^{2}$, François Roch ${ }^{3}$, \\ Patrick Todeschini ${ }^{4}$ and Yves Brechet $^{1}$ \\ ${ }^{1}$ Laboratoire SIMAP, Domaine Universitaire, Saint-Martin d'Hères, France \\ 2 Institute of Materials Science and Technology, Vienna University of Technology, Austria \\ ${ }^{3}$ AREVA NP, Materials, Chemistry and Technology Department, Paris La Défense, France \\ ${ }^{4}$ EDF R\&D, Département MMC, Groupe Métallurgie, Les Renardières, France
}

\begin{abstract}
The goal of this study is to understand the complex microstructures which form at the interface between a low-alloy steel and a stainless steel during welding and subsequent heat-treatment at $610^{\circ} \mathrm{C}$. A dual approach with both experimental measurements and thermodynamic and kinetic modeling has been chosen for both solidification and solid-state phase transformations. A very good agreement has been obtained for the carbon profile across the interface and the nature of phases which form.
\end{abstract}

\section{CONTEXT OF THE STUDY}

The pressure vessel of the French nuclear power plants is made of low-alloy steel. By submerged arc welding, it is internally covered by a cladding of stainless steel for protection against corrosion. The solidification of this complex dissimilar interface gives rise to a large variety of microstructures. Our work aims at understanding their formation during solidification and their evolution during post-welding heat-treatment. Starting from the base metal, one meets successively a narrow layer of martensite, a purely austenitic zone and then the duplex $\delta / \gamma$ microstructure of the stainless steel.

\section{MICROSTRUCTURES FORMATION DURING WELDING}

Wavelength Dispersive Spectroscopy (WDS) profiles reveal compositional gradients in the weld near the interface. It highlights the incomplete mixing of the molten base metal (Fe and C-rich) and the filler metal ( $\mathrm{Cr}$ and Nirich) over a transition layer of about $150 \mu \mathrm{m}$ large. Near the fusion line, low contents of substitutional elements are responsible for the formation of the martensitic layer during rapid cooling after welding.

As shown by solidification calculations, the purely austenitic structure near the interface is unexpected. The primary solid to precipitate from the liquid should be $\delta$ ferrite. But rapid heating during welding could prevent the $\gamma \rightarrow \delta$ transformation of the base metal, which acts as a substrate for the weld to grow epitaxially. This epitaxial growth has been underlined by a study of the orientation relationships between the martensitic laths in the base metal and the adjacent austenitic grains in the weld metal by Electron Backscatter Diffraction. Orientation mapping coupled with parent grains reconstruction based on the martensitic daughter grains [1] has allowed evidencing the continuity of the austenitic grain boundaries across the fusion line. Moving away from the interface, microsegregations reveal a change from $\gamma$ to $\delta$ primary solidification. Both the built-up of solute in the intercellular space and the under-cooling at the tip of the growing dendrites [2] were calculated by a thermodynamic and kinetic model. The computational result of this phase competition corresponds to the observed microstructural changes.

\section{PHASE TRANSFORMATIONS DURING HEAT- TREATMENT}

The dissimilar weld is then subjected to a heat-treatment at $610^{\circ} \mathrm{C}$ (between 3 and 16 hours) in order to release the stresses accumulated during welding and temper the heat affected zone. Because of the gradient in the chemical potential of carbon $(\Delta \mu=62500 \mathrm{~J} / \mathrm{mol})$ across the interface, carbon diffuses from the base metal $(\mathrm{w}(\mathrm{C})=$ $0.18 \mathrm{wt} . \%)$ towards the weld metal $(\mathrm{w}(\mathrm{C})=0.052 \mathrm{wt} . \%)$. On the low-alloyed side, carbon migration leads to the dissolution of cementite and the coalescence of the bainite laths together with an abnormal grain growth of the remaining ferrite grains. Carbon enters into both the martensitic band and the purely austenitic zone leading to the precipitation of $\mathrm{Cr}$-rich carbides.

\section{Design of the model:}

In order to forecast and quantify carbon diffusion across the interface, we have developed a mesoscopic model, which has been implemented into the software MatCalc [3]. It is based on Onsager's equation, which postulates a linear dependence between the flux $\mathrm{J}_{\mathrm{k}}$ of a specie $\mathrm{k}$ and the chemical potential gradients $\mu_{\mathrm{i}}$ of all 
species present in the system. The following system of partial differential equations is solved on each node of the one-dimensional mesh using a finite difference method of discretization:

$$
\left\{\begin{array}{l}
\frac{\partial C_{k}}{\partial t}=\frac{\partial}{\partial z}\left(-J_{k}\right) \\
J_{k}=-\sum_{j=1}^{n-1} D_{k j}^{n} \frac{\partial C_{j}}{\partial z}
\end{array}\right.
$$

The diffusivity matrix $\boldsymbol{D}_{\boldsymbol{k} j}^{\boldsymbol{n}}$ contains thermodynamic and kinetics contributions, which are calculated at each node in space at each time step from appropriate databases. The calculation consists in two steps: diffusion is first solved inside the matrix phases (BCC and FCC) only, then thermodynamic equilibrium allows calculating the phase fractions of the different phases by minimization of the Gibbs free energy of the system. Three different carbides $\left(\mathrm{Fe}_{3} \mathrm{C}, \mathrm{M}_{7} \mathrm{C}_{3}\right.$ and $\left.\mathrm{M}_{23} \mathrm{C}_{6}\right)$ are taken into account. The matrix composition is changed after precipitation and a new step of diffusion is performed.

\section{Results and comparison with experiments:}

The heat-treatment of interest consists of 8 hours at $610^{\circ} \mathrm{C}$. The heating and cooling steps between 400 and $610^{\circ} \mathrm{C}$ have also been taken into account with a ramping of $30{ }^{\circ} \mathrm{C} /$ hour. The results of the simulation are presented on figure 1, for both the carbon content (a) and the nature and volume fractions of the carbides (b). The model is able to forecast a complete decarburization of the base metal over $200 \mu \mathrm{m}$, together with the dissolution of cementite over the same distance. It is in perfect agreement with the microstructural observations and the carbon measurements by both WDS and SIMS (Secondary Ion Mass Spectroscopy). The model also predicts a heavy precipitation of mostly $\mathrm{M}_{7} \mathrm{C}_{3}$ carbides in the martensitic layer, and a precipitation of $\mathrm{M}_{23} \mathrm{C}_{6}$ carbides in the austenite over $100 \mu \mathrm{m}$. This is also fully consistent with the observations. The nature of carbides has been studied on carbon extraction replicas by Transmission Electron Microscopy assisted by the ACOM (Automated Crystal Orientation Mapping [4]) software. An intense precipitation of large $\mathrm{M}_{7} \mathrm{C}_{3}$ carbides $(100-200 \mathrm{~nm})$ has been found in the martensitic layer, whereas small coherent $\mathrm{M}_{23} \mathrm{C}_{6}$ precipitates $(20 \mathrm{~nm})$ are visible in the austenitic matrix. A 3D reconstruction of the carbides population in the martensitic layer has also been performed by serial cutting with a Focused Ion Beam (FIB).

\section{CONCLUSION AND PERSPECTIVES}

The thermodynamic and kinetic models developed for the prediction of both the solidification microstructures formation and their evolution during subsequent heattreatment have been successfully implemented and agree
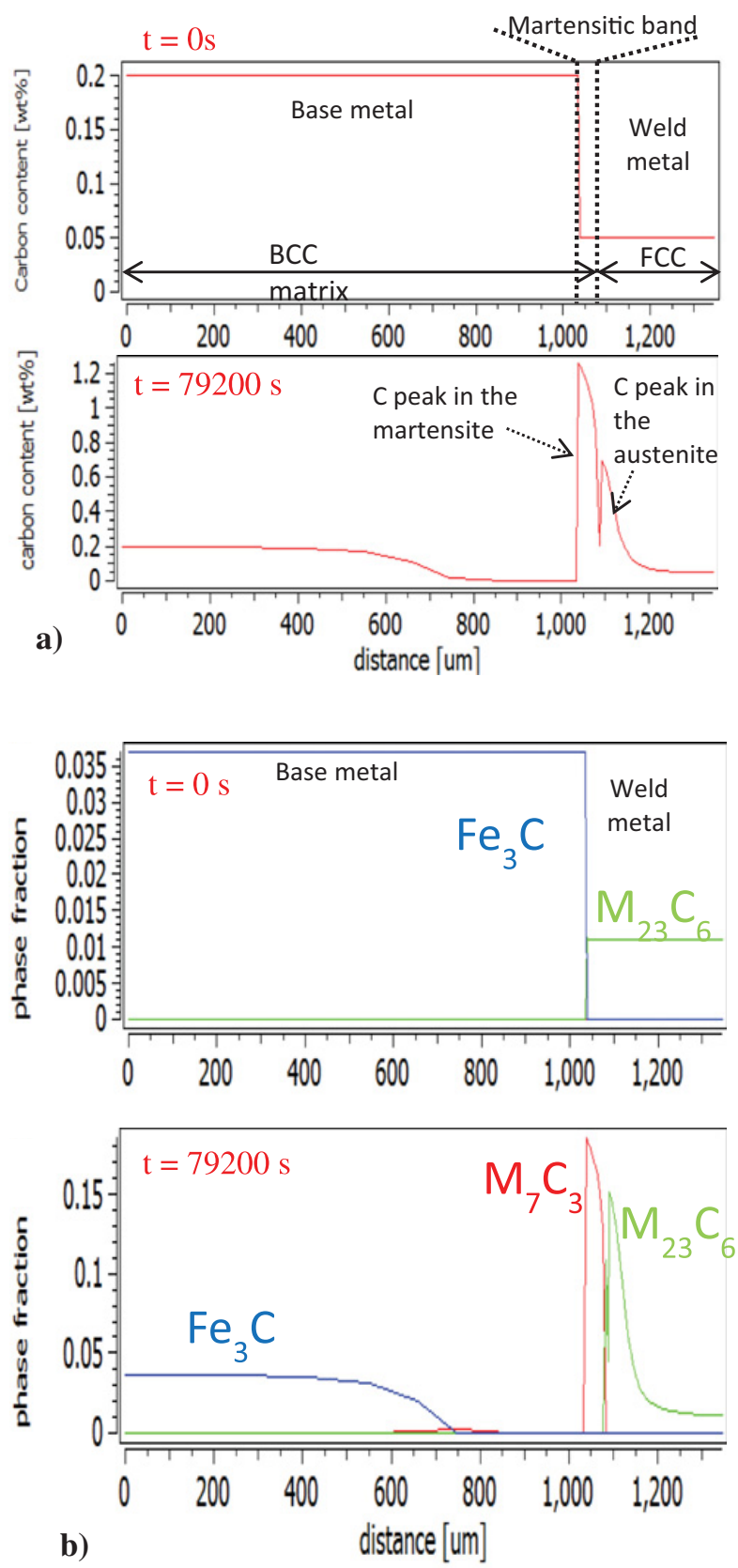

Figure 1. Computational results. a) Carbon content across the weld interface (wt.\%). b) Nature and volume fractions of carbides around the interface.

well with the experimental measurements. Concerning precipitation, up to now, the equilibrium volume fractions have been considered to be reached instantaneously. The results in terms of volume fractions are close to those obtained by TEM and FIB. The next step in modeling will be to take into account precipitation kinetics with the classical sequence of nucleation, growth and coarsening. The objective is to be able to predict the size distribution of precipitates. Our goal is to provide for a multi-component system, with a realistic description of the thermodynamics, 
a complete coupling between long-range diffusion across the weld and local precipitation.

\section{References}

[1] C. Cayron, Journal of Applied Crystallography 40, 2007, 1183-1188
[2] M. Bobadilla, J. Lacaze, G. Lesoult, Journal of Crystal Growth 89, 1988, 531544

[3] E. Kozeschnik, B. Buchmayr, Mathematical Modelling of Weld Phenomena 5, 2001, 349-361

[4] E.F. Rauch, M. Veron, Solid State Phenomena 186, 2012, 13-15 